\title{
Vocational language learning and teaching at a South African university: Preparing professionals for multilingual contexts
}

\author{
Pamela Maseko and Russell Kaschula \\ Rhodes University, School of Languages: African Language Studies Section, P.O. Box 94, 6140 Grahamstown \\ E-mail: p.maseko@ru.ac.za; r.kaschula@ru.ac.za
}

\begin{abstract}
This paper highlights the methodology that has been used at Rhodes University and other South African universities in implementing vocation-specific African language learning programmes. Essentially, the paper links the curriculum design to the theoretical paradigm of intercultural communication. Intercultural theory is used as a basis to develop vocation-specific courses where language and culture are taught, for example, to second language learners of isiXhosa at Rhodes University. These courses include courses for Pharmacy and Law students. This paper offers a new theoretical paradigm for intercultural language teaching. Furthermore, examples from specific courses are provided in order to illustrate how this theoretical paradigm can be implemented in a practical way. The impact of multilingualism and intercultural communication in the wider legal and healthcare work environment in South Africa is also discussed.
\end{abstract}

Keywords: vocational language learning, indigenous African languages, multilingualism, intercultural communication, cultural awareness, cultural sensitivity, legal professional, health-care professional, law, pharmacy

\section{Introduction}

The Constitution of the Republic of South Africa (1996) recognises eleven of South Africa's most spoken languages as official languages of the country. Of these, nine are indigenous African languages and are spoken by about $80 \%$ of the total population. The other two English and Afrikaans - were the only official languages of the pre-democratic regime and are spoken by a large part of the remainder of the population. However, when it comes to institutions of higher learning, the common trend in South Africa in terms of linguistic composition is the reverse. About $80 \%$ of the total student population have English or Afrikaans as their home language, whilst the minority are speakers of indigenous African languages, and the majority of institutions of higher learning have English and Afrikaans as languages of learning and teaching (LoLT). Taking this linguistic reality into account, it is clear that vocational language training at tertiary level is imperative.

The problems that monolingual South African professionals encounter in providing services in a language not understood by their clients are enormous, and are well documented - see, for example, Crawford (1999) and Levin (2005). Our education system produces 
professionals who are largely incompetent in the languages of the clients they serve and, consequently, their service is lacking and less informed by their clients' needs. There are generally very few effective language programmes that equip student-professionals with communicative skills in the context of their profession. Where these exist, they are generic language programmes which focus on the structure of the language, and less on the specific communication needs of the students (Maseko 2007b). Simply put, students trained in South African institutions of higher learning are not able to cope in South Africa's multilingual and multicultural environment as they are not able to provide a service to the majority of the people they are supposed to serve, i.e. those speaking indigenous African languages.

In this paper we discuss language intervention programmes undertaken by Rhodes University (RU) in the Eastern Cape Province, programmes that address the language challenges, and the difficulties experienced by monolingual South African professionals during intercultural communication. These vocational language learning programmes are taught in the Faculties of Law, Pharmacy and Education and in the School of Journalism and Media Studies.

The language interventions discussed in this paper were primarily developed within Rhodes University's South Africa-Norway Tertiary Education (SANTED) Multilingualism Project. The Project is a joint venture between the Norwegian government and the South African national Department of Education. It is hosted by the African Language Studies Section in the School of Languages, within the Faculty of Humanities of RU. Its aim, inter alia, is to promote multilingualism through the acquisition of isiXhosa as an additional language.

In this paper we focus only on the Law and Pharmacy programmes. We will show how this vocational language learning intervention can inform the legal and health-care work environment in the broader South Africa.

\section{The multilingual nature of South African society: legislative context}

Section 6 of the South African Constitution (1996), in proclaiming eleven languages as official languages of the Republic, points to the multilingual nature of the South African society. Further, it requires that other political, social and educational institutions develop their own language policy and plans that express the sentiments of the Constitution, namely unity, tolerance, linguistic and cultural diversity and sensitivity.

In the context of education, the Language-in-Education Policy (LiEP) (1997) that applies to general education is meant to facilitate learning and teaching of languages in a manner that diminishes the linguistic and cultural barriers that were sanctioned by the apartheid administration for almost fifty years (Heugh 2000). The language policy that dictates language practices in higher education institutions (HEIs) derives from the LiEP. Of particular relevance to this paper is the National Language Policy Framework for South African Higher Education (2001) and the Report on the Development of Indigenous Languages as Mediums of Instruction in Higher Education (2003). Both these policy documents lay bare the complexities of languages in South Africa but also make recommendations that pertain to the learning and teaching of languages at HEIs. Of relevance in this paper is the promotion of multilingualism through the teaching of African languages as additional languages, especially in professional disciplines, and the unearthing of indigenous knowledge systems and cultural issues that are important and should inform language learning 
in these disciplines. It is in this context that we approach the teaching of IsiXhosa for Law and IsiXhosa for Pharmacy at RU.

\section{Why universities are better placed to implement multilingualism}

Through multilingual learning and teaching universities can promote transformation, linguistic tolerance and cultural sensitivity in higher education. This responsibility is appropriate to universities mainly because of their principal function as centres of research, enquiry and development. As vocational training institutions, they can also influence the employment market by using the linguistic ability of their graduates as a selling tool.

In a context such as the one sketched above, South African universities can play a significant role in implementing multilingualism in the education milieu, thereby influencing linguistic change at universities and in society in general. Our multilingual reality requires that tertiary training institutions adapt their learning programmes so as to include training in an African language. This training should equip students with language proficiency in as well cultural awareness of and sensitivity towards the target African language.

In the present environment, the inability of South African university-trained professionals to operate effectively in a multilingual context is a barrier to effective provision of services. Failure of professionals to provide services effectively to markets with different languages and cultures is an enormous impediment. Crawford (1999), Ellis (1999) and Levin (2005), in their respective research on communication problems in South African health-care facilities, report instances where patients and doctors are helpless and disillusioned. There is ineffective communication between doctors and their patients as they do not understand each other's culture and language. The relationship between a health-care professional (HCP) and his/her client requires communication, but meaningful communication is only possible through a language that is intelligible to both the interlocutors.

In the case of South Africa, where vocational training in higher education does not equip students to communicate with their non-English-speaking clients, power relations come into play when they are required to interact with these clients. In the interaction, the HCP occupies a higher position in the communication hierarchy, because of their social, economic, professional and language position. The client is disempowered, especially in terms of language: during the whole interaction the client is passive and the conclusion reached at the end of a consultation is less, if at all, informed by their own version of events, or narrative of their circumstances. In cases where the HCP uses interpreting services (as is common in South Africa's health-care facilities) this service, although handy, is rife with its own problems - mainly that it does not facilitate the client's voice (Maseko 2007b). The conditions referred to here can lead to HCP and, especially, client despondency as the result is often misinterpretation of facts and loss of meaning, amongst other things (Crawford 1999; Levin 2005). These conditions are not restricted to HCP-patient interaction and can be transferred to other domains, e.g. job interviews and lawyer-client interaction. Kaschula and Anthonissen (1995) offer an illustrative example from the legal context when they refer to a case in which a term referring to a specific cultural practice of amaXhosa was misunderstood. The isiXhosa term ukondla - which refers to nurturing and bringing someone up as your own, i.e. traditional adoption - was misinterpreted as "to feed" in a court of law in which Kaschula was 
the lawyer of the defendant. In this case, the defendant who was claiming insurance benefits from an insurance company on behalf of her deceased daughter, lost the case.

The present South African tertiary education system, where vocational training takes place, perpetuates this scenario. As mentioned earlier, although our focus in this paper is on RU, which is responding to this challenge, similar interventions are taking place at other universities, for example, in the Health Sciences Faculty of the University of Cape Town; the Psychology, Dental Assisting and Education departments at the University of KwaZulu-Natal; and in Pharmacy at the University of Stellenbosch and the University of the North West. In the case of South Africa, language learning linked to vocational training seems to be the most appropriate route to follow if the prevalent language challenges in the country are to be met head-on. Cases like the ones referred to above, which result in intercultural miscommunication, are rife in South Africa. One wonders whether the vocation-specific expertise and knowledge acquired in vocational training institutions is sufficient if one is not able to transfer it in the language best understood by one's client. In this paper we argue that it is the role of universities, as vocational training institutions, to incorporate appropriate language proficiency and cultural sensitivity programmes as important aspects of vocational training. It is our view that this is indeed possible, as we will show with reference to the IsiXhosa for Law and IsiXhosa for Pharmacy programmes at RU. Importantly, because knowledge of the relevant language and culture is acquired in the context of the vocation in which it will be used, these courses yield immediate benefit for students because of their instrumental value. The courses draw together several disciplines of conventional study, e.g. the acquisition of (generic) additional languages, sociolinguistics, and the acquisition of vocation-specific terminology, and therefore linguistic, pragmatic and meta-abilities are acquired in the process.

\section{Rhodes University: historical and linguistic background}

RU's choice of LoLT and languages to be taught as additional languages, as well as the University's general language practices, need to be understood not only in terms of the political legislative context set out above, but also in terms of the University's linguistic context. To contextualize the linguistic composition of the University, we will start by providing some demographics of the Eastern Cape Province in which the University is situated.

\subsection{The Eastern Cape Province and surrounding areas}

According to the census of 2001, the Eastern Cape Province comprises about $16 \%$ of South Africa's total population of about 48 million (Statistics South Africa 2003). The black population in the province totals about $87 \%$, and about $83 \%$ of these people have isiXhosa as their home language. As indicated by these statistics, isiXhosa is the dominant language in the province. Besides isiXhosa, Afrikaans and English are the other official languages, with English as the main language of business (Statistics South Africa 2003).

If one looks at Grahamstown, where RU is situated, it is a microcosm of the Eastern Cape Province. The general trend in South African language statistics is that about $80 \%$ of the total population are speakers of African languages. This is the case at national level, at provincial level and at regional level as well. Therefore, in Grahamstown, about $80 \%$ of the population have isiXhosa as their home language. 


\subsection{Rhodes University's linguistic composition}

The Data Management Unit of RU provides statistics regarding the home language of the students. The dominant home language of the students at RU is English, with about $64 \%$ of the students indicating this as their home language. $15 \%$ of students indicated that they have isiXhosa as their home language. Afrikaans, according to these statistics, is home language to just over $2 \%$ of the student population. The total number of students speaking indigenous African languages is 1,747. IsiXhosa is the most spoken, with 907 students, followed by Shona (260 students), isiZulu (159 students) and Setswana (119 students). There are seven other indigenous African languages spoken at RU, with numbers of speakers ranging between three and eighty-eight (Data Management Unit 2007).

The language statistics above suggest that RU is a linguistically and culturally diverse institution, but that English is still the dominant language. The various policies of the University are sensitive to this diversity and capitalize on it to make it a university that "recognises its southern African setting and the need to meet the international standards in a non-racial society" (2006, see http://www.ru.ac.za/about/). The Language Policy of RU, as approved by the University Senate and Council in 2005, is one such policy.

\subsection{Rhodes University's Language Policy (2005)}

The RU Language Policy is responsive to the present language prevalence internationally, nationally and in the province and, for this reason, uses English as the LoLT. At the same time, it is also mindful of the geographical position of the University and the national political agenda, and provides for the development and promotion of the other languages of the Eastern Cape Province - isiXhosa and Afrikaans.

The main objectives of the Language Policy are to promote proficiency in English as the LoLT at the University, to recognise and advance the academic viability and status of isiXhosa, English and Afrikaans, to promote multilingualism and sensitivity in language usage among all members of the University, and to provide appropriate support for the development of academic literacy among students to whom English (the LoLT) is not their home language (RU Language Policy 2005).

As indicated earlier, RU prides itself in community engagement, amongst other things. The University's commitment to community engagement is illustrated in the practical preparation given to students in vocation-specific disciplines such as Law and Pharmacy. The IsiXhosa for Law and IsiXhosa for Pharmacy programmes discussed here are designed to equip professionals with linguistic and cultural knowledge, pertaining especially to isiXhosa, so that they are sensitive to and able to cope in the multilingual South African context. The two language intervention programmes are offered by the African Language Studies Section which, as its brief from the RU Language Policy, seeks to promote the acquisition of isiXhosa within the institution.

In the following section we discuss the theoretical paradigm within which the language learning programmes are framed. 


\section{An intercultural communication paradigm}

A new type of communication seems to be emerging in South African society. This involves the renegotiation of both new and old identities. With reference to this, Collier (1997:36-44) distinguishes between avowal and ascription processes:

Avowal is the self an individual portrays (i.e., saying, "This is who I am"), whereas ascription is the process by which others attribute identities to an individual (e.g. through stereotypes). The avowal and ascription processes acknowledge that identity is shaped by our own and by others' communicated views of us. Identities are also expressed through core symbols, norms, and labels (Collier 1997:40).

According to Ochs (2005:79), "the relation of language to social identity is not direct but rather mediated by the interlocutors' understandings of conventions for doing particular social acts and stances..." In the isiXhosa courses that are being developed and offered at RU, this is intrinsically bound to the way in which the students see the learning experience as a window for new identity development. This identity is born out of the need for a support base and a need to reach out in the work place, which supersedes racial and cultural differences. Pharmacists, for example, need to reach out to their patients who come from different language and cultural backgrounds. They are, therefore, required to learn the language, and be sensitive to the culture of the people they interact with in their profession. The educational environment at RU, for example, where initial isiXhosa learning takes place, is aimed at facilitating this process.

In the teaching of the isiXhosa courses, we try to first establish the notion of "identity security" and "familiarity" prior to easing the students into the communicative event. The teaching of culture-specific traits plays a crucial role in the vocation-specific language programmes, since intercultural miscommunication between a service provider and a client can affect (amongst other things) the medicine-taking behaviour of a client, in the case of a pharmacist, or the ruling in a court of law, in the case of a lawyer.

Given the strong link between social identity and learning of an additional language (see Norton 2000), the interactions that take place in the multilingual isiXhosa learning context at RU can be considered intercultural. Scholars sometimes use the terms "cross-cultural" and "intercultural" interchangeably; however, there are differences. According to Gudykunst (2003:159-160):

Cross-cultural research involves comparing behavior in two or more cultures... Intercultural research involves examining behavior when members of two or more cultures interact... Intercultural behavior often is compared with intracultural behavior (i.e. behavior within a culture).

Gudykunst (2003:163) continues by pointing out that: "Intercultural communication generally is conceptualised as communication between people from different national cultures...intergenerational communication, communication between members of different social classes, and inter-racial/inter-ethnic communication." This type of communication, therefore, unravels the communication process between two or more different cultural groups embedded within a common environment. 
Ting-Toomey (1993:1-2) argues that, as part of her "identity negotiation theory," the more secure individuals' self identification is, the more they will be open to interacting with people from other cultures. The more vulnerable they feel, the more anxiety they will experience in such interactions. The University itself should be creating the setting, i.e. a common space which breeds a sense of in-group communication, even though participants come from differing cultures. The RU programmes show that people can learn to interact despite their differences and the perceived stereotypes that may exist in society.

To conclude this section, we will delineate the extent of the unpreparedness of graduates for coping with the South African multilingual and multicultural environment. We will quote from Dr Michael Levin, a medical doctor practising in Cape Town's paediatric hospitals and wards, where the majority of his patients speak isiXhosa, but the doctors are monolingual speakers of English. Levin conducted a study in which parents of patients were asked to fill in questionnaires on issues that they considered as barriers to health-care. The findings in his study illustrate the dangers that exist because of linguistic (and maybe cultural) handicaps of doctors. He states that

the ... interviews showed that isiXhosa-speaking patients experience significant barriers to optimum health care. They ... encounter significant difficulties in communication with doctors and vice versa. A lack of same language medical practitioners... leads to the majority of interviews being conducted in a language the patients cannot fully understand... Patients are dissatisfied with communication between themselves and doctors, and have difficulty understanding doctors, making themselves understood, and asking questions. Doctors are dissatisfied with communication between themselves and their patients (Levin 2005:301).

Although Levin points to the fact that it is both the doctors and the patients who are frustrated, Crawford (1999) contends that the patients are in a worse position. She states that in a doctorpatient relationship, power relations come into play. The doctor not only occupies a higher rank in the hierarchy of the communicative event because of his or her profession, but $s /$ he is also probing the patient's body in a language that is inaccessible to the patient. The patient occupies a disempowered position $-\mathrm{s} / \mathrm{he}$ is at the bottom of the hierarchy and as a result, in the whole interaction, s/he is passive and the diagnosis reached and the treatment furnished at the end is less informed, if at all, by their own perception and description of their illness.

Crawford further argues that where a doctor and a patient do not share a common language or world view, the cultural knowledge and other aspects of information are omitted, especially social information, which is not necessarily "detected" from the physiology or the symptoms of the patient's illness, but is highly significant in reaching a diagnosis and deciding on treatment,. Needless to say, and as rightly stated by Levin, the conditions outlined above can lead to both the service provider (in this case, the doctor) and, especially, the client (in this case, the patient) becoming despondent because of misunderstanding and loss of meaning.

\section{Rhodes University IsiXhosa for Law and IsiXhosa for Pharmacy: a case study}

RU's Pharmacy and Law Faculties are leading in the University in terms of their dedication to community engagement, which forms part of practical and vocational training for students in 
these Faculties. Given the linguistic and cultural diversity within and outside of the institution, the University needed to respond to the language needs of the students appropriately. The main purpose of these language programmes is to facilitate linguistic and cultural sensitivity, tolerance and diversity so that students are prepared to cope in the multilingual South African context upon completion of their vocational training.

\subsection{An intercultural discipline-related teaching model}

All the isiXhosa additional language programmes have been designed with a view that language and culture affect how we see the world and how we communicate about the world we see. The way we see the world is what we reflect to others when we communicate with them - it is our own way of seeing things which is often in conflict with the "other's" way of seeing things.

The teaching approach itself focuses on two crucial issues in intercultural communication. Firstly, we focus on creating a relaxed and supportive environment for learning. We hope that this will in turn encourage our students to use their newly acquired language skills confidently and appropriately, thus creating a more comfortable environment for communicating with isiXhosa-speakers within the University, in community engagement and, most importantly, in providing a service to isiXhosa-speaking clients when they are qualified professionals. Secondly, particularly in discipline-specific courses, besides language learning, we also focus on cultural aspects which, as noted by Ting-Toomey (1999), form what is perhaps the most crucial component of intercultural communication.

In the following section we discuss the language intervention programmes that specifically promote multilingualism and intercultural communication in the area of Pharmacy and Law at RU.

\subsection{IsiXhosa for Pharmacy}

Final year students training as pharmacists in the Faculty of Pharmaceutical Sciences have an opportunity to take an isiXhosa course as part of their curriculum. The IsiXhosa for Pharmacy programme was designed and developed in close co-operation with the Pharmacy Administration and Practice (PAP) course of the Pharmacy curriculum. Final year students in the Faculty are required to participate in the Community Experience Programme (CEP) - a programme that gives students an opportunity to "practise" their pharmaceutical skills and knowledge. In the CEP students are required to interact with clients with chronic conditions around the Grahamstown area.

Given the linguistic composition of the Grahamstown area, a large majority of the people who make use of this service are isiXhosa-speakers. The students are required to interact with them around their socio-economic conditions and medicine-taking behaviour pertinent to their chronic conditions. During these visits, students are required to take clients' personal information, social history, medical history and history of chronic condition and an account of medication used, and to also provide advice on medicine-taking behaviour and other aspects relevant to the client's health.

The IsiXhosa for Pharmacy programme is designed in such a way that it ties in with the PAP programme. It is designed to equip the Pharmacy student with the necessary proficiency skills to enable them to cope in interactions with clients where isiXhosa is spoken. It specifically 
equips them with linguistic skills, as well as cultural knowledge that will not only facilitate communication in an HCP-client interaction, but will also make them aware of common cultural practices in isiXhosa that could affect the medicine-taking behaviour of their clients. In other words, the course provides students with an opportunity for language learning, which is applied, both linguistic and cultural, and vocation-specific. The Pharmacy students are enabled to use this linguistic and cultural knowledge with their clients in accessing the knowledge acquired in their Pharmacy training.

The themes around which linguistic communication is structured include socio-economic factors affecting medicine-taking behavior, instructions on taking medication, awareness of symptoms and management of chronic conditions like asthma, tuberculosis, diabetes, hypertension and epilepsy. An example of cultural knowledge is knowledge of the common practice of consulting amagqirha (traditional healers) and common forms of treating an illness among amaXhosa. The course makes the participants aware that traditional healers are part of the community of amaXhosa and are commonly consulted for healing, sometimes even before a western-trained HCP (Ngubane 1977; du Pisani 1998; Maseko 2007a). The following is an excerpt from an introductory lesson on illness, treatment and healing amongst amaXhosa, which illustrates how cultural issues are raised in the course book:

The person amongst amaXhosa who is mostly consulted for treatment of disease or illness, besides a western-trained health care professional, is a traditional healer. A traditional healer can be seen before or after a doctor has been consulted. If consulted, their medicine is often taken alongside that of the western doctor. It is strongly argued by scholars of the indigenous knowledge systems that most of the medicine prescribed by the traditional healers has healing properties. Their medication is often made from roots, leaves and bark of special plants which is crushed and mixed with water, or dried leaves which can be used as incense.

The most common ways of treatment in which these medicines can be used are: purgative (ukugabha, forced vomiting and ukucima, enema), steam treatment (ukufutha) and ritual body wash (ukuhlamba ngeyeza). As a health care professional, one should be aware of this and should become attentive during consultation if the client is taking traditional medicine and caution and advise appropriately against those that can be detrimental to the condition of the client. For example, there are reports that during the steam treatment, which requires a client to stand over hot medicinal water, some patients have had an epilepsy attack and injured themselves (Maseko and Mapi 2007).

The IsiXhosa for Pharmacy course was introduced in 2007. After the first cohort of students, it was evaluated by the Centre for Higher Education, Research Teaching and Learning (CHERTL) of the University, and the students' feedback was highly affirmative. The students in the course felt that taking the course enabled them to learn another language as well as the culture embedded in it. They also commended the fact that the course was vocation-specific in that it prepared them for what to expect when interacting with their clients. One student commented that the "course contributes towards development of skills needed by professionals in the field", and another stated that it "breaks language barrier and helps in the patient-pharmacist interviews, to develop a good trusting relationship between the two." There were also strong views that even though the context was pharmacy, the generic language also enabled them to speak with amaXhosa generally (CHERTL Teaching and 
Course Feedback for IsiXhosa for Pharmacy Evaluation 2007). IsiXhosa for Pharmacy is now being offered as a credit-bearing course to final year Pharmacy students.

\subsection{IsiXhosa for Law}

Students in the Law Faculty are also required, as part of their practical training and community involvement, to provide services to clients who need legal assistance at RU's Legal Aid Clinic (LAC) in Grahamstown. The people who use the LAC's services have low incomes and the majority of them are isiXhosa-speaking.

The objectives of the course are to provide students with law-specific language communication skills, knowledge and skills which will be necessary for them to understand and interpret cultural issues embedded in isiXhosa communication, especially those which are relevant to the specific context of law, and to further provide them with isiXhosa knowledge and a foundation that they can build on when they are in the field as practising legal professionals.

Some of the linguistic communication skills taught in the course are on the themes of civil and criminal law, e.g. child maintenance, credit default and theft, which are common in the LAC context. The following excerpt from the course book illustrates some of the cultural issues that are raised, as part of language learning. The excerpt is from a lesson on child maintenance amongst amaXhosa. The context is that the LAC receives complaints from unmarried women who often consult them for child maintenance. The male partners, who are often accused of not providing financial support for the child, respond by saying ndasihlawula isisu ("I 'paid' for the pregnancy"). The cultural input of the theme on Child Maintenance follows:

A child amongst amaXhosa normally is always sheltered, and the way of life of the society allows for the child to always be protected, provided for, and brought up in an environment where there is nurturing and a caring guardian.

When an unmarried woman falls pregnant, her family normally "reports" the matter to the family of the man who impregnated her, to inform them about the pregnancy, and to claim intlawulo yesisu (i.e. "payment" as acknowledgement of pregnancy). If the man accepts responsibility, he is required by custom to pay the girl's family for the "damage" caused to the girl, in the form of cattle (nowadays it is usually in the form of money). This is the only formal contribution that the father makes towards the child.

Once a man has paid for the pregnancy, and if he does not ask for the girl's hand in marriage, the child born out of wedlock is then raised/adopted (ukukhuliswa) by his/her maternal family. S/he will assume his/her maternal family name, clan name and practise their customs even if his/her father is known. Even if the woman were to get married to someone else, the child would remain in this home, and is normally brought up by maternal grandparents. So amongst amaXhosa, traditionally, there is no "illegitimate" child.

The practise of ukuhlawula isisu, however, has to be viewed alongside the present child maintenance laws in South Africa (Maseko 2007a).

As with the IsiXhosa for Pharmacy course, the IsiXhosa for Law course was introduced in 2007 and has since been offered as a credit-bearing course to penultimate and final year Law students. The evaluation of the course indicates that the students' ability to communicate with 
their clients, even in taking their personal and social history, builds trust between them and their clients. They have reported that sensitivity to cultural issues also enables them not to impose their worldview upon the clients. The course has also equipped them with skills to be able work appropriately with the interpreter - "the interpreter does not replace the client, she is there to facilitate the interview process, not to take over. If I cannot understand, I ask [the interpreter] to assist, but now, unlike in the past, I can identify some words, and I can ask if I think [the interpreter] has left out some information" (Departmental student evaluation 2008).

\section{Conclusion}

The above discussion on teaching additional languages in vocational training contexts points to the necessity of developing intercultural language programmes at universities by focussing on the learning and teaching of African languages as additional languages. The point of departure is the constant juxtaposition of one cultural knowledge and language against the other. Thereafter emerges the interrelatedness and interconnectedness of the two, brought on by a changing society and social environment which, in turn, contributes to a changing South African university and work environment. Such clashes of culture may initially have traumatic consequences, prior to the emergence of a comfortable space accommodating both sets of beliefs.

Nevertheless, even though intercultural communication may have its challenges, the onus is now on South African universities to take control of the multilingual debates surrounding language implementation as emanating from Section 6 of the South African Constitution. These institutions should be at the forefront of intellectual debates concerning language and learning. Partly, this involves implementing viable language policies that contribute positively to the tertiary learning environment and consequently the work environment. There is an onus on universities to create a learning context that benefits South Africa's developing economy and democracy. The issue of language remains central in this endeavour.

\section{Acknowledgement}

The language intervention programmes reported in this paper are the result of a generous financial grant received from the South Africa-Norway Tertiary Education (SANTED) Multilingualism Programme. For this reason, we would like to acknowledge them.

\section{References}

Abrams, J., J. O'Conner and H. Giles. 2003. Identity and intergroup communication. In W.B. Gudykunst (ed.) Cross-cultural and intercultural communication. Thousand Oaks / London / New Delhi: Sage Publications. pp. 209-224.

Collier, M.J. 1997. Cultural identity and intercultural communication. In L.A. Samovar and R.E. Porter (eds). Intercultural communication: A reader. San Francisco: Wadsworth. pp. 36-44.

Collier, M.J. and E. Bornman. 1999. Core symbols in South African intercultural friendships. International Journal of Intercultural Relations 23: 133-156.

Crawford, A. 1999. "We can't all understand the whites' language": an analysis of monolingual health services in a multilingual society. International Journal of the Sociology of Language 136: 27-45.

Dalvit, L., S. Murray, B. Mini, A. Terzoli and X. Zhao. 2005. Computers and African Languages in Education: Eternal Enemies or Newly Found Friends? An ICT Tool for 
the Promotion of African Languages at a South African Institution. Perspectives in Education 23(4): 123-131.

Du Pisani, E. 1998. Some aspects relating to medical beliefs and health behaviour in a black urban setting. Paper presented at the conference of the Association for Anthropology in Southern Africa, Rhodes University, Grahamstown.

Ellis, C. 1999. Learning Language and Culture in the Medical Consultation. Parktown North: Sue McGuiness Communications.

Gudykunst, W.B. 2003. Issues in cross-cultural communication research. In W.B. Gudykunst (ed.) Cross-cultural and intercultural communication. Thousand Oaks / London / New Delhi: Sage Publications. pp. 149-161.

http://www.ru.ac.za/about/dedication.html accessed on 25 August 2006.

http://www.ru.ac.za/about/flash/history.html accessed on 25 August 2006.

Heugh, K. 2000. The case against bilingual and multilingual education. PRAESA Occasional Paper No. 6. Cape Town: PRAESA.

Kaschula, R.H. and C. Anthonissen. 1995. Communicating across cultures in South Africa: Towards a critical language awareness. Johannesburg: Hodder \& Stoughton.

Levin, M. 2005. Discordant definitions of medical terminology and their impact on communication between English-speaking doctors and Xhosa-speaking parents at a paediatric hospital. Unpublished Ph.D. thesis, University of Cape Town.

McLaren, M.C. 1998. Interpreting cultural differences. The challenge of intercultural communication. Dereham, Norfolk: Peter Francis Publishers.

Maseko, P. 2007a. IsiXhosa for Law. Unpublished course guide, Rhodes University, Grahamstown.

Maseko, P. 2007b. Vocational language learning and how it relates to language policy issues. Unpublished Master's research. Rhodes University, Grahamstown.

Maseko, P. and Mapi, T. 2007. IsiXhosa for Pharmacy. Unpublished course guide, Rhodes University, Grahamstown.

Ngubane, H. 1977. Body and mind in Zulu medicine: an ethnography of health and disease in Nyuswa-Zulu thought and practice. London: Academic Press.

Norton, B. 2000. Identity and language learning: Gender, ethnicity and educational change. Harlow: Longman.

Ochs, E. 2005. Constructing social identity: A language socialization perspective. In S.F. Kiesling and C.B. Paulston. (eds). Intercultural discourse and communication. The essential readings. Malden / Oxford / Victoria: Blackwell Publishing Ltd. pp. 78-91.

Stephan, C.W. and W.G. Stephan. 2003. Cognition and affect in cross-cultural relations. In W.B. Gudykunst (ed.) Cross-cultural and intercultural communication. Thousand Oaks / London / New Delhi: Sage Publications. pp. 111-126.

Ting-Toomey, S. 1993. Communicative resourcefulness: An identity negotiation theory. In R.L. Wiseman and J. Koester. (eds). Intercultural communication competence. Newbury Park, CA: Sage Publications. pp. 72-111.

Ting-Toomey, S. 1999. Communicating across cultures. New York / London: The Guilford Press. 


\section{Biographical note}

Pamela Maseko is a lecturer and the co-ordinator of the South Africa-Norway Tertiary Education Development (SANTED) Multilingualism Project at Rhodes University in Grahamstown, South Africa. She has taught IsiXhosa as an Additional Language, Translation Studies and Sociolinguistics at Rhodes University and the University of Cape Town, specialising in curriculum design for vocation-specific language learning programmes. Russell Kaschula is the Head of the School of Languages and Professor of African Languages at Rhodes University in Grahamstown, South Africa. He has taught African Oral Literature, Sociolinguistics and IsiXhosa as an Additional Language at various universities in South Africa and abroad. He has authored various books and papers on his research interests. 